\title{
NEW APPROACH TO THE TECHNOLOGICAL ASPECT OF CORPORATE SUSTAINABLE DEVELOPMENT
}

\author{
Rolandas DREJERIS ${ }^{1}$, Danguolè OŽELIENĖ ${ }^{2}$ \\ Management department, Vilnius Gediminas Technical university, Lithuania \\ E-mails: ${ }^{1}$ rolandas.drejeris@vgtu.lt (correspondingauthor); ${ }^{2}$ d.ozeliene@vvf.viko.lt \\ Received 10 May 2019; accepted 20 May 2019
}

\begin{abstract}
Enterprises that seek for sustainable development should align economic interests with environmental and social requirements. It is not enough to take into account just these basics components. Technology plays a significant role in company activity. The aim of this article is to highlight the relationship between the dimensions characterising sustainability and to take a deeper look at the structure of the concept of sustainability, so that to understand in more detail the completeness of the dimensions of sustainability. For achieving this aim is necessary through the analysis of researchers' opinions to apply the logical assessment, systematisation, and comparison of information, selects the most important information describing the sustainability of technology, highlights the relationships between the technological aspect of sustainability and other sustainability dimensions, evaluates the technological processes of the corporate product in terms of sustainability, clarifies and presents arguments highlighting the importance of the technological aspect in sustainable business activity, rejects inappropriate arguments, identifies links between the arguments, and, basing on the information, proves and/or formulates anew some logical considerations to justify the full competency of the technological dimension in the sustainable development framework. Article proved that sustainable development contains the technological dimension which is added to the four classical dimensions and serves as an axis that determines the contents of other sustainability parts.
\end{abstract}

Keywords: technology, sustainable activity, dimensions of sustainability, technological sustainability, sustainable business model.

JEL Classification: C52, E61, O33, M20, Q56, Q01.

\section{Introduction}

Research studies into sustainable development are interdisciplinary in nature and, as such, are connected with social and economic development solutions, technological progress, environmental protection, and changes in modern society and its life (Melnikas 2010). By providing justification of the importance of the need for knowledge in the formation and development of organisational culture, this author shares the view of other researchers and supports the notion that it is appropriate to analyse the technological dimension as it may be critical in the formula of sustainable business. Many researchers use three-dimensional definition to express sustainable activity: environmental, economic and social. However, it is evident that sustainable development covers more than those three areas as it is based on harmony between people, planet and profit. What expression does this harmony take? Efforts to systematically review the structure of sustainable activity and discovering also justifying a potentially new concept of sustainability expression are necessary, because this issue is relevant and its solution is often crucial in evaluating various business situations for both business practitioners and theorists.

In light of the moderate economic growth over recent centuries, people might have forgotten the fact that economy is dependent on the planet's ecosystems. Growing global environmental pollution has been the first signal showing that economic development may have serious consequences for future generations, and such preconditions have determined the emergence of the concept of sustainable development (Paul at al. 2014). A more categorical view is that the economic system is completely dependent on the ecosystem

Copyright (C) 2019 The Authors. Published by VGTU Press.

This is an Open Access article distributed under the terms of the Creative Commons Attribution License (http://creativecommons.org/licenses/by/4.0/), which permits unrestricted use, distribution, and reproduction in any medium, provided the original author and source are credited.. 
(Barbien 2013). Recently, a sustainable organisation is becoming one of the most popular and ambitious concepts, because the environment and organisations are closely linked, and long-term success of organisations depends on how sustainably they are able to integrate into environment. 'Therefore, not only economic, but also corporate environmental solutions are treated as part of sustainable development. Porter and Kramer (2011) have come up with the idea of creating a shared value, proving that solving social problems can be financially beneficial for companies and that social solutions need to be found at company level in order to achieve sustainability. However, if the focus is only on the economic and environmental aspects of organisations, sustainable development loses the essence of wholeness. Therefore, a lot of attention has been recently paid to the institutional dimension of sustainability, the content of which provides for existence of the necessary legislation and its implementation, and opportunities for the equal use of social, economic and environmental resources. Research has shown that corporate social, economic and environmental issues, when interlinked directly, can only be addressed at institutional level, and, therefore, the concept of institutional dimension was proposed more than a decade ago to express sustainable development (Spangenberg and Lorek 2002). The importance of institutional sustainability has also been emphasised by other authors (Bleischwitz 2003, Baumgartner and Rauter 2017) who argue that namely leaders are responsible for making policy decisions within an organisation, implementation of eco-efficient innovations, control of activities and regulation of mechanisms for the development of social welfare for members of the organisation and society. The lack of certainty in defining sustainability of activity and the vague identification of leaders' responsibility call for the need to highlight the relationship between the dimensions characterising sustainability and to take a deeper look at the structure of the concept of sustainability; so that to understand in more detail the completeness of the dimensions defining sustainability. That would be the aim of this article, which would be expressed by the search for a more modern concept of sustainability.

To achieve this aim of the article through the analysis of researchers' opinions is necessary to apply the methods of logical assessment, systematisation, and comparison of information, to select the most important information describing the sustainability of technology, to highlight the relationships between the technological aspect of sustainability and other sustainability dimensions, to evaluate the technological processes of the corporate product in terms of sustainability, to clarify and present arguments highlighting the importance of the technological aspect in sustainable business activity, to reject inappropriate arguments, to identify links between the arguments, and, basing on the information, to prove and/or formulate a new some logical considerations to justify the full competency of the technological dimension in the sustainable development framework.

\section{Reasoning of the need for the technological di- mension to describe company's sustainable activity}

In the modern world of competitive economies, the term technology becomes increasingly common even in everyday life to describe both global business processes and individual activities.

The concept of technology is treated differently by scientists from different branches of science, so the choice of technology is also usually assessed only in narrow scientific spheres. Science does not provide an overall impact of technology on other business processes and their results. In light of the rising cost of production factors and the decreasing number of working people, low-cost-based competitiveness loses its sense and leads to reorientation towards the need to develop new technologies. Recently, the interest in sustainable activities has increased, and even the leaders of new companies are looking for sustainable technology opportunities. Therefore, this fact calls for the need to assess the place of technology in the system of sustainable business. The relevance of the problem is in question about the relationship between different dimensions of sustainable business, which is unclear for the leaders of companies, determined our decision to carry out deeper research in this area.

Technologies focused on sustainability principles (conservation of resources, reuse and recycling of products, improvement of energy efficiency, reduction of negative impacts on the environment and pollution, etc.) are generally considered to be sustainable. Looking at the issue in the broader context, we can see the need to apply another dimension to the definition of sustainability of company's activity that would embrace all of these aspects. In order to combine the environmental, social and institutional dimensions of sustainable development, the article attempts to introduce a technological dimension of sustainability in order to provide its full description. Below we discuss the logical arguments that emphasise the importance of the technological dimension and position it as one of the most important in the system of corporate sustainable development. Further argumentation is based on the relationship between sustainable technology and certain business elements.

\subsection{Relationship between sustainable technology and business model}

From a general point of view, technology is defined as the transformation of processes, materials or information resources into necessary end products or services. There can be many ways of transformation, and they are improved 
daily to reduce costs, increase sales, improve product (service) quality, and reduce production cycles. Technological advancement is triggered by natural evolutionary processes based on the principles of selection (Fox 2018). The more general concept business model expresses the way of creating value for customers. It describes how a company creates value for the customer. In addition, the business model reflects the business logic of a company, showing what the company offers its customers and what relationships it has with its partners (Witjes and Lozano 2016). Business models change over time; they become more diverse and improve. In addition, while the choice of a business model depends primarily on the nature of business, commercial solutions are always geared towards increasing the profit of the business entity and the choice of business technology must therefore match that need (Bohnsack and Kolk 2014). There are different commercial product-making technologies that can be applied to the chosen business model. Accordingly, any business entity seeking to apply a sustainable business model in its activity must first of all choose the appropriate sustainable product-making technology that will determine the level of sustainability of its business. As product technology is more sensitive to the need for innovations (Robinson et al. 2016), new (or upgraded) technologies may even require a replacement of the existing business model (Bohnsack and Kolk 2014) that has been introduced in the company, for example, a few years ago.

The most important scientific achievements have become time-independent, and that is why science is developing extremely rapidly today, leading, in turn, to the emergence of new technologies. This is conditioned by the use of highly globalised investment in innovations and the accelerated speed of information transmission. Social systems are also changing rapidly. This has to do with population growth, urbanisation and market relations. Such dynamism of the environment has the power of influencing changes in the globalised economy determined by the emergence of new technologies. Technology is a key to the success of companies in achieving their goals and properly performing their production or service activities. Thus, elaborating further on the concept of technology, it can be said that technology is a system of operations of a certain work objects where work implements are used to turn it into a work product. Work objects are changing and develop into new ones as products of scientific and technical progress. Growing consumer needs necessitate not only improvement of work objects, but also of work implements, which leads to improving product quality. Therefore, constant changes and improvements in product technologies are driven by growing consumer demands. These circumstances call for the need for sustainable business technologies.
Entrepreneurs seeking to develop a sustainable business always face challenges that include the choice of a business model, a sustainable business strategy, as well as solutions related to the choice of business technology. The issues relating to the choice of business technology have been quite widely discussed in scientific literature. The choice-making process consists of classical evaluation stages, the main ones of which are the identification of the technology alternatives to be evaluated, the selection of evaluation criteria that depend on the nature of the activity, the determination of the significance of the criteria, etc.

Organisations using the same business model can simultaneously use several, even different, product-making technologies. Manufacturing of different types of products usually involve the use of different production technologies. A sustainable business model requires the use of only sustainable technologies, and if at least one production process is not sustainable (for example, eco-unfriendly), it will render to the whole business model unsustainable (Bohnsack and Kolk 2014). These authors also state that in applying sustainable technologies, organisations often use different business models to turn the qualities of sustainable technology into tools for creating new economic value.

Having decided to follow the direction of sustainability, the leaders of organisations, as well as start-ups seeking sustainable business development, must first choose a sustainable technology or adjust a known classic performance technology to greater sustainability. This implies that technology determines the nature of the business and at the same time can be a business model determinant. Hence, manufacturing or service technology is the key aspect of business sustainability.

The choice of product-making technology is a challenging task especially for business start-ups. In addition, the global dynamics of technological changes does not leave without challenges the leaders of business, too, if they care of their business development, because it is important to select the production technology appropriate for the market so that to meet the constantly changing needs of consumers. Moreover, the choice of technology is influenced by changes in the attitudes of both business and its product consumers towards environmental issues and changes in prices for fossil fuel. The choice of technology means not only choosing what the company will do, but also how it will do, with what implements, when, and what it will start from. The answers to these questions have direct effects on corporate sustainability. Denton (2014) argues that companies make a fundamental ethical mistake in their activities if their business disregards environmental friendliness. He stresses that this mistake has a negative impact on business performance. This author continues to be categorical: companies often carry out unsustainable business because they do not understand the impact of technology on sustainability; the 
researcher emphasises that technology is the main expression of sustainability (Denton 2014). This logical argument alone raises the need to mention the technological aspect in the concept of sustainability. Given that product technology determines the nature of the business model, technological sustainability appears to be the most important phenomenon in sustainable company's activity, and this argument places the technological dimension among the key dimensions of sustainability.

\subsection{Relationship between the technological aspect of sustainability with other dimensions of sustainability}

The concept of properly selected technology in the broad sense should include the proper implementation of both environmental and social business solutions. It can be said that technology basically covers the content of those concepts and can be regarded as an even more important feature describing the sustainability of actions. Sustainable business has its own values and characteristics, mostly related to strict compliance with environmental requirements, solving social problems in a manner favourable to company's staff and society and determination to carry out company's economic activities justly and fairly. But all these characteristics of sustainable business development are closely related to the choice of business technology. In other words, the essence of sustainable business technology is more general in its content, as it covers solution of environmental, social and economic problems and brings these phenomena together. Therefore, it is the main dimension of sustainability that characterises business sustainability as a feature of a certain activity. After all, technological solutions appear to be the most important in addressing environmental problems of a sustainable business entity. The chosen product technology can also have an impact on the company's social values and, at the same time, on the shaping of a positive image. It is evident that technological solutions also determine company's economic opportunities. Again, these factors demonstrate the importance of technology as an aspect of sustainability in the company's sustainable commercial activity and bring the company's product technology alongside the most important environmental, social, institutional and economical dimensions characterising sustainability of the company's practice.

However, in order to assess the need for the technological dimension in sustainable activity, it is appropriate to agree with the concept of sustainability provided by Kates et al. (2012). When explaining the essence of sustainability, these authors mention, inter alia, the technological dimension as one of the most important aspects expressing the content of sustainability. They discern a systematic link between environmental, social and business technological solutions. The attempts of other authors to describe business sustainability cannot be overlooked either. For example, Seghezzo (2009) offers to describe sustainability using five dimensions which, originally formulated, criticise the paradigm of sustainability limited to environmental, social and economic dimensions. Seghezzo (2009) criticises the quite philosophically mentioned three-dimensional definition of sustainability by the World Commission on Environment and Development (WCED) by highlighting the apparent content contradictions between these dimensions. He offers to define a sustainable business entity in terms of place containing the three dimensions of space $(\mathrm{x}, \mathrm{y}, \mathrm{z})$, permanence as the fourth dimension of time, and the fifth, human dimension representing personnel in sustainable activity. Despite the strictly philosophical attitudes to such a definition of the dimensions of sustainability, from the point of view of practical business, the article can be seen as providing the justification of the need for the technological dimension to describe business sustainability. All the five dimensions proposed by Seghezzo (2009) are at the same time consistent with the definition of the concept of technology. It can be therefore concluded that the author highlights technology as the key (or even the only one) dimension characterising sustainability which is clearly divided into components.

From the social point of view, sustainable and ecofriendly economic development is only possible if the development is planned and implemented through the maximum use of eco-friendly and environmentally beneficial technologies. Social relations in any organisation and their intensity can also be influenced by the chosen technology and some environmental factors (Hitomi 2017). This author also highlights the superiority of technology as it can determine, inter alia, the quality of social relations within an organisation. Likewise, the social aspect can be influenced by technologies the progress of which is reflected in a more efficient use of resources and reduction of environmental damage, while at the same time increasing the outputs and outcomes of the activities, i.e. improving the quality of life.

The importance of intellectual capital, continuous learning, and knowledge sharing are attributed to the social factors that determine the sustainable development of an organisation. According to Choo (2006) and Vegera et al. (2018), the base of appropriate and timely acquired knowledge, continuous acquisition of new knowledge and effective knowledge management within organisations contribute to the most rational economic decisions, to the transformations of reality into sustainable development, as well as to the application of new technologies for business sustainability and to the creation of new technologies for better consumer satisfaction and creation of a competitive advantage. Therefore, it is clear that the social sustainability approach not only is not in conflict with but, on the contrary, facilitates the expression of company's sustainability in the technological dimension. 
The impact of business technology on company's social relations and culture has already been clearly and convincingly stated (Vergragt 2006). When explaining the concept of technology, the author of this monograph stresses that technology basically encompasses three meanings: tools/ instruments, knowledge and culture. To explain the impact of cultural and social relations on technology, he emphasises that technological development goes ahead societal development. Therefore, there separation between technology and culture is no longer meaningful. All human activities, like housing, nutrition, transportation, work, leisure, even art and imagination, become heavily enmeshed with cutting-edge technology (Hard and Jamison 2005). As we are living in an "age of technical and technological culture", even our deepest and most private knowledge and emotions are permeated by advanced technologies without which the sustainability of activity in the social domain is simply impossible (Vergragt 2006). Therefore, this circumstance also confirms the need for the technological dimension to be necessary for defining sustainability in social terms.

Discussions about the relationship between solving economic growth, environment and social issues of an organisation are long-lasting, complex and so far remain irresolvable. In essence, these issues include operational technology and, therefore, the inclusion of this component in the definition of sustainability is necessary in this respect, too. Natural resources are scarce and nature's generosity is not limitless; beyond a certain limit, it is becoming increasingly difficult to extract its wealth. Work creates and produces goods, provides services, but work is also a scarce resource which is dependent on population, length of working age, education, qualification, etc. Therefore, some new technologies are needed to achieve sustainability in natural processes. In this light, the technological aspect becomes not only necessary but also inevitable to achieve sustainability both in the nature and in human activities.

\subsection{Relationship between sustainable technology and sustainable innovations}

Sustainability of activity is increasingly associated with the concept of technology and the assessment of the need for innovation. Creation and implementation of innovations to achieve business sustainability also involves modification of business technology or creating a new business model with new business technology. Application of the latest information technologies is typically directed specifically at enhancing the sustainability of business operations (Krintz et. al. 2016, Dong et al. 2010 etc.), in addition to various other smart technologies which are also being developed to improve operational sustainability (Foley et al. 2017, Höjer and Wangel 2015). Application of the latest innovative technologies allows processing large amounts of data for making appropriate decisions (Kuo-Jui et al.
2017, Ahearn et al. 2016). There also are other types of technologies, like high technology, nanotechnology, green technology, innovative technology, digital technology, robotic technology, etc., most of which also are (or may be) targeted at enhancing sustainability of activity. Thus, the change in the content of the essence of technology that defines particular actions, even the change in the concept, over time triggers the need to incorporate the technology aspect into the definition of sustainability, and to include the technological dimension into the corporate sustainability framework. Since business development is usually associated with the use of innovative technologies, implementation of new technologies serves, from the point of view of sustainability, as an axis around which revolve other solutions that determine sustainability.

Most of sustainable innovations implemented in companies are aimed at modifying the product technology of the company towards better environmental or social relations. Application of instruments reducing pollution, alternative energy sources as well as other environmentally friendly instruments is related to the improvement of product technology. When investigating the implementation of product innovations in companies aimed at increasing the sustainability of their actions, some authors encountered the need to improve technology first of all (Schulte and Hallstedt 2018). The aforementioned authors argue that sustainability is enhanced through the use of innovative production methods, tools, processes, and even by changing the approach to the existing operations. Reviewing the possible models of sustainable innovative operations in companies, they eventually arrive at the conclusion that the basis of sustainability is the choice of appropriate advanced technology allowing application of sustainable processes only (Schulte and Hallstedt 2018).

Preconditions for improving sustainable competitive performance in small- and medium-sized enterprises have been examined by Ma Degong et al. (2018). Their research has inter alia confirmed that innovative technologies have the greatest impact on competitiveness enhancement processes. The afore-mentioned authors explored the peculiarities of applying internationally recognised, advanced technologies in small- and medium-sized enterprises in emerging economies. The results of the research have highlighted the technological aspect as the main feature of sustainability, and described the innovativeness of technology as a determinant of performance sustainability. Other researchers also explain the importance of technology for sustainable development and the impact of sustainable technology on the competitiveness of the company (Cheng and Li 2018). These authors examine in detail how the application of green technologies in Chinese manufacturing companies contribute to the better relative economic performance of the companies using such technologies by comparing the 
values of their performance indicators with those of other traditional businesses.

The key task of sustainable development is to look for solutions to rationally allocate scarce resources in order to guide the economic system along the optimal path. Therefore, investing in new innovative technologies can bring social, environmental and financial benefits for the company (Crosno and Cui 2014). As the surrounding environmental potential is almost completely exhausted, especially in the area of raw materials and energy sources, it is becoming increasingly evident that the path to further development in a limited environment is to make the most efficient use of strategic resources, i.e. knowledge. This fact calls for the need for technology as a new aspect of sustainability. Only new sustainable technologies based on new innovative knowledge can be the basis of future business, and this fact demonstrates the need for incorporating the technological dimension in the formula of business sustainability.

Implementation of innovations for achieving business sustainability is in many cases linked to a change in productmaking technology. Therefore, technological development appears to be a determinant not only for the opportunities of implementing innovations but also for the need thereof. Accordingly, the technological aspect is obviously a necessary dimension to express sustainability in terms of innovation implementation.

\subsection{Relationship between sustainable technology and $s$ of product-making performance}

The chosen sustainable technology also determines performance, i.e. not only the quantity and quality of the production sold, but also the smoothness of production which is consistent with the needs, the number of employees required, the time of production and other indicators (Baumgartner and Rauter 2017, Tetsman et al. 2017). It has already been mentioned that a product of sustainable activity is better rated by consumers and such product brings greater added value to business. This fact has been confirmed by numerous research studies and is not even debated in scientific literature. The use of renewable energy resources and other eco-friendly measures determine the choice of production (or service) technology. Water management, sanitation, transport, production and use of energy, production issues, communication, use of agricultural commodities, education and health care issues, and other components of the company's activities can be regarded as the basis of sustainable technology the level of sustainability of application of which is seen by many researchers as a determinant of the company's performance.

Eschenfelder et al. (2016) basically supports the inclusion of the technological dimension into the concept of sustainability, confirming that technology determines the degree of sustainability of company's practice and, consequently, its performance. Those authors argue that it is very important for companies to define and adhere to the exact process standards when selecting business technology. Research by these authors has confirmed that properly defined standards allow mitigating the negative impact on the environment and reducing the cost price of the product. When looking for opportunities to reduce cost price, the most important task is not to impair the quality of the product by the means chosen. Even a slight reduction in cost price leads to better sustainable performance (Eschenfelder et al. 2016). Therefore, this argument also confirms the importance of the technological dimension in sustainable activity of companies. From the point of view of performance, other research not only recommends, but also confirms the need to integrate the technology component into the sustainability formula (Sammalisto et al. 2015). These authors interviewed employees from Swedish universities about their experience in sustainable activities in order to highlight the importance of three components (environmental, social and economic) in sustainable development. The presented conclusions of respondents' answers made it possible to understand, inter alia, the need for the accuracy of technology in company's activities and provided arguments for the need and importance of the technological dimension in sustainable development.

\subsection{Relationship between the Fourth Industrial revolution and sustainability of activity}

As mentioned, technologies always go first and businesses often have to catch up. This is particularly evidently explained by the supporters of the arguments for the so-called Fourth Industrial Revolution. According to its author Schwab (2017), it is no longer an application of one invention to the industry as it was before, as new production methods are constantly emerging. And the emergence of new technologies is gaining momentum. The ever-increasing digitalisation of industry forces companies to rethink their production process, as manufacturing and information technologies become ever more intertwined. It is widely argued that the Fourth Industrial Revolution has to do with merging technologies that are fusing the physical, digital and biological worlds. Digital industry, robotic and automated factories with many tasks would being done by machines and robots under human supervision. These are the most obvious consequences of the digital revolution, also referred to as Industry 4.0. They will change not only the world we live in or the understanding of the work we do, but will also influence the way we live or even think. Historically, every major industrial revolution has in fact changed not only the face of industry but that of society as well. Values like speed, efficiency, reduced production costs, the value and nature of human work have fundamentally 
changed the way we live, consume, or learn. As the need for business sustainability has long been proven, it means that the subject-matter of such a digital revolution will be the instruments for meeting the mentioned need. According to Lee et al. (2018), the Fourth Industrial Revolution cannot yet be well defined, but it clearly embraces smart factories, cyber-physical systems, new distribution and acquisition systems, new systems for product and service development, adaptation to human needs, and corporate social responsibility for business sustainability. The Fourth Industrial Revolution has a creative link between technologies and markets in all industries based on the use of information technologies However, the characteristics of Industry 4.0 can only be fully defined when technical-technological innovations are combined with institutional and social innovations. Most technologies become commodities or common resources. Emerging interrelationships between technology and information systems are becoming more important for sustainability than each of technologies taken separately, because such relationships have greater effects on sustainability indicators in terms of the Fourth Industrial Revolution (Yun 2017). Hence, other authors (Lee et al. 2018, Yun 2017) confirmed the influence of the technological aspect on the sustainability of activity and in this respect the technological dimension should also be one of the main components of sustainability.

\section{Corporate sustainable development model}

In many countries, governments take efforts to promote the implementation of sustainable technologies through lower taxes on companies or other benefits for sustainable activities. Unsustainable technologies have retained the reputation of the 20th century due to high costs and low reliability. Various forms of advanced technologies are sought and achieved every day, with an increasing proportion of the public supporting their implementation.

The concept of sustainability is not static; it evolves along with developing societies, states, processes, products and thinking. The classical dimensions (environmental, social, institutional, and economic) that characterise sustainability do not fully identify the processes needed to achieve sustainability. For example, in scientific literature, the environmental, institutional and social dimensions basically define the requirements for sustainable movement. According to Dobrovolskiene et al. (2017) the economic dimension expresses company's sustainable performance and also defines the requirements for economic processes.

There is an apparent lack of an axis that would combine the necessary sustainability actions into one whole defining the necessary processes of corporate sustainable business. Therefore, there is a need to present an updated corporate sustainability structure in the form of a model (Figure 1).

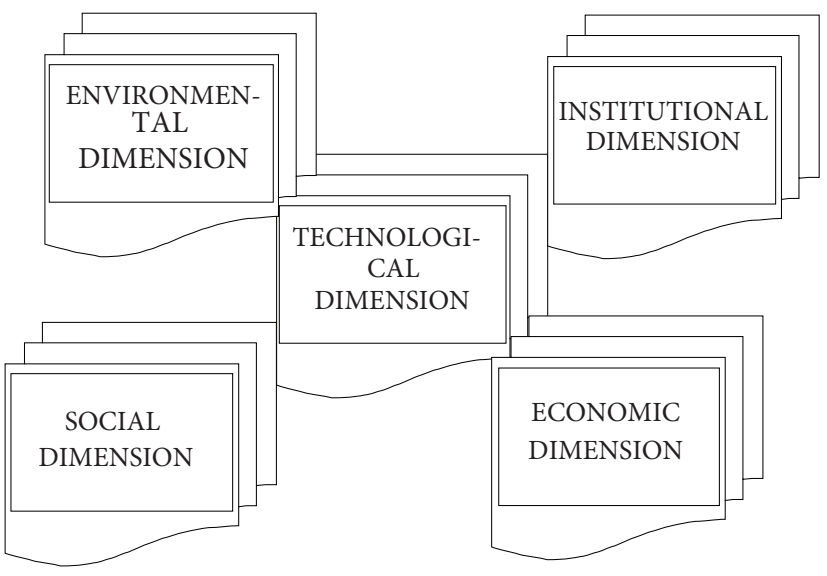

Figure 1. A model of corporate sustainable development

It has already been proven in numerous publications that Corporate Sustainable Development is closely linked to the use of modern technologies. An important aspect of global progress is shorter time from the creation of new technology until its uptake. But modern technologies can also bring unwanted results in terms of sustainability (Manariotis and Yannopoulos 2004, Morrison-Saunders and Fischer 2009).

Therefore, corporate business can be sustainable only if companies not only apply reliable technical-technological processes but also apply them (or use the results) properly without causing damage to the environment. Hence, the fact that a particular application of technology may lead to sustainable activity only confirms the importance of technology in the context of sustainability and the need to incorporate the technological dimension into the concept of sustainable development.

\section{Conclusions}

The description of sustainable development limited to four dimensions only (environmental, social, institutional, economic) is not systematically complete, because the lost element of the system, which combines in its expression the aforementioned dimensions, is quite important in explaining the processes of sustainability of company's activity. The missing element of the system is the technological dimension.

Relying upon the results of researchers exploring corporate sustainable development with a view to identifying the place of the technological component in the system of corporate sustainable development, this article explains the relationship between sustainable technologies and business model, the relationship between the technological aspect and other sustainability dimensions, the relationship between technology and the concept of sustainable innovations, the relationship between technology and performance, and the relationship between sustainability of activity and the provisions of the Fourth Industrial Revolution. 
The results of the study helped to find some arguments about the importance of technology in the system of sustainability. The highlighted arguments prove the evident need for the technological dimension. The presented model of corporate sustainable development contains the technological dimension which is added to the four classical dimensions of sustainability and serves as an axis that determines the contents of other sustainability dimensions.

\section{Disclosure statement}

Authors declare that they have not any competing financial, professional, or personal interests from other parties.

\section{References}

Ahearn MC, Armbruster W, Young R (2016) Big data’s potential to improve food supply chain. Environmental sustainability and food safety. International Food and Agribusiness Management Review 19 (18): 155-172.

Barbien D (2013) What makes an enterprise sustainable? Nuremberg Information systems (University of Erlangen) 1: 38-46.

Baumgartner RJ, Rauter R (2017) Strategic perspectives of corporate sustainability management to develop a sustainable organization. Journal of Cleaner Production 140 (1): 81-92. https://doi.org/10.1016/j.jclepro.2016.04.146

Bohnsack R, Kolk A (2014) Business models for sustainable technologies: Exploring business model evolution in the case of electric vehicles. Research Policy 43 (2): 284-300. https:// doi.org/10.1016/j.respol.2013.10.014

Bleischwitz R (2003) Cognitive and institutional perspectives of eco-efficiently. Ecological Economics 46 (3): 453-467. https:// doi.org/10.1016/S0921-8009(03)00186-1

Cheng Z, Li W (2018) Independent R and D, Technology introduction, and green growth in China's manufacturing'. Sustainability 10: 3-11. https://doi.org/10.3390/su10020311

Choo CW (2006) The Knowing organization. How organizations use information to construct meaning, create knowledge and make decisions (2nd ed). Oxford: Oxford University Press.

Crosno, JL, Cui AP (2014) A multilevel analysis of the adoption of sustainable technology. Journal of Marketing Theory and Practice 22 (2): 209-222. https://doi.org/10.2753/MTP10696679220213

Denton P (2014) Technology and sustainability. Toronto: Rocky Mountain Books.

Dobrovolskienė N, Tvaronavičienė M, Tamošiūnienė R (2017) Tackling projects on sustainability: a Lithuanian case study, Entrepreneurship and Sustainability Issues 4 (4): 477-488. https://doi.org/10.9770/jesi.2017.4.4(6)

Dong B, Lam KP, Höynck M, Zhang R, Chiou Y-S, Benitez D (2010) An information technology enabled sustainability test-bed (ITEST) for occupancy detection through an environmental sensing network. Energy and Buildings 42 (7): 1038-1046. https://doi.org/10.1016/j.enbuild.2010.01.016

Eschenfelder KR, Shankar K, Williams R, Lanham A, Salo D, Zhang M (2016) What we talking about when we talk about sustainability of digital archives, repositories and libraries?
In: Proceedings of the 79th ASIST annual meeting: creating knowledge, nhancing lives Through information technology. Copenhagen, Denmark, October 14-18 (148): 1-6. https://doi. org/10.1002/pra2.2016.14505301148

Foley A, Smyth BM, Pukšec T, Markovska N, Duić N (2017) A review of developments in technologies and research that have had a direct measurable impact on sustainability considering the Paris agreement on climate change. Renewable and Sustainable Energy Reviews 68 (2): 835-839. https://doi. org/10.1016/j.rser.2016.11.215

Fox SJ (2018) Policing - the technological revolution: opportunities and challenges! Technology in Society 56: 69-/7. https:// doi.org/10.1016/j.techsoc.2018.09.006

Hard M, Jamison A (2005) Hubris and hybrids; a cultural history of technology and science. New York: Routledge.

Hitomi K (2017) Manufacturing systems engineering. A unified approach to manufacturing technology, production management and industrial economics. London: Routledge. https:// doi.org/10.1201/9780203748145

Höjer M, Wangel J (2015) Smart sustainable cities: definition and challenges. In: Hilty LM \& Aebischer B (Eds). ICT Innovations for sustainability advances in intelligent systems and computing. New York: Springer. https://doi.org/10.1007/9783-319-09228-7_20

Kates RW, Parris TM, Leiserowitz AA (2012) What is sustainable development? Goals, indicators, alues, and practice. Environment: Science and Policy for Sustainable Development 47 (3): 8-21. https://doi.org/10.1080/00139157.2005.10524444

Krintz C, Wolski R, Golubovic N, Lampel B, Kulkarni V, Sethuramasamyraja B, Roberts B, Liu B (2016) Smart farm: improving agriculture sustainability using modern information technology. In: Proceedings of KDD Workshop on Data Science for Food, Energy, and Water https://sites.google.com/ site/2016dsfew/home

Kuo-Jui W, Ching-Jong L, Ming-Lang T, Ming KL, Jiayao H, Kimhua T (2017) Toward sustainability: using big data to explore the decisive attributes of supply chain risks and uncertainties. Journal of Cleaner Production 142 (2): 663-676. https://doi.org/10.1016/j.jclepro.2016.04.040

Lee MH, Yun JH, Pyka A, Won DK, Kodama F, Schiuma G, Park HS, Jeon J, Park KZ, Jung K, Yan M-R, Lee SY, Zhao $\mathrm{X}$ (2018) How to respond to the Fourth industrial revolution, or the Second Information Technology revolution? Dynamic New combinations between technology, market, and society through open innovation. Journal of Open Innovation: Technology, Market, and Complexity 4 (3): 21-23. https:// doi.org/10.3390/joitmc4030021

Ma D, Ullah F, Khattak MS, Anwar M (2018 ) Do international capabilities and resources configure firm's sustainable competitive performance? Research within Pakistani SMEs. Sustainability 10: 82-98. https://doi.org/10.3390/su10114298

Manariotis I, Yannopoulos P (2004) Adverse Effects on Alfeios river basin and an integrated management framework based on sustainability. Environmental Management 34: 261-269. https://doi.org/10.1007/s00267-004-0069-y

Melnikas B (2010) Sustainable development and creation of knowledge economy: the new theoretical approach. Technological and Economic Development of Economy 16 (3): 516-540. https://doi.org/10.3846/tede.2010.32 
Morrison-Saunders A, Fischer TB (2009) What is wrong with EIA and SEA anyway? A sceptic's perspective of sustainability assessment. Journal of Environmental Assessment Policy and Management 08 (1): 19-39. https://doi.org/10.1142/9789814289696_0011

Paul ID, Bholeb GP, Chaudharic JR (2014) A review on Green manufacturing: it's important. Methodology and its Application. Procedia Materials Science 6: 1644-1649. https://doi. org/10.1016/j.mspro.2014.07.149

Porter M, Kramer MR (2011) The big idea: creating shared value. Harvard Business Review 89 (1/2): 62-77.

Robinson WG, Chan PW, Lau T (2016) Sensors and sensibility: examining the role of technological features in servitizing construction towards greater sustainability. Construction Management and Economics 34 (1): 4-20. https://doi.org/10.1080/01446193.2016.1139146

Sammalisto K, Sundström A, Holm T (2015) Implementation of sustainability in universities as perceived by faculty and staff - a model from a Swedish universities. Journal of Cleaner Production 106: 45-54.

https://doi.org/10.1016/j.jclepro.2014.10.015

Schulte J, Hallstedt SI (2018) Self-Assessment method for sustainability implementation in product innovation. Sustainability 10: 12-36. https://doi.org/10.3390/su10124336

Schwab K (2017) The Fourth industrial revolution New York: Crown Business.
Seghezzo L (2009) The five dimensions of sustainability. Environmental Politics 18 (4): 539-556. https://doi.org/10.1080/09644010903063669

Spangenberg JH, Lorek S (2002) Environmentally sustainable household consumption: from aggregate environmental pressures to priority fields of action. Ecological Economics 43: 127-140. https://doi.org/10.1016/S0921-8009(02)00212-4

Tetsman I, Bazienė K, Viselga G (2017) Technologies for sustainable circular business: using crushing device for used tires. Entrepreneurship and Sustainability Issues 4 (4): 432-440. https://doi.org/10.9770/jesi.2017.4.4(3)

Vegera S, Malei A, Sapeha I, Sushko V (2018) Information support of the circular economy: the objects of accounting at recycling technologicfigureal cycle stages of industrial waste. Entrepreneurship and Sustainability Issues 6 (1): 190-210. https://doi.org/10.9770/jesi.2018.6.1(13)

Vergragt PV (2006) How technology could contribute to a sustainable World. Boston: Tellus institute.

Witjes S, Lozano R (2016) Towards a more circular economy: proposing a framework linking sustainable public procurement and sustainable business models Resources. Conservation and Recycling 112: 37-44. https://doi.org/10.1016/j.resconrec.2016.04.015

Yun JJ (2017) Business model design compass: open Innovation funnel to Schumpeterian New ombination business model developing circle. Cham (Switzerland): Springer. https://doi.org/10.1007/978-981-10-4128-0_11 